\author{
Pawel Żukowski \\ Zakład Organizacji i Zarządzania \\ Wyższa Szkoła Zarządzania i Administracji w Opolu
}

\title{
Model i symulacja dynamiki systemu zarządzania organizacją gospodarczą (ujęcie modelowe)
}

Sprawne i efektywne zarządzanie organizacją gospodarczą w warunkach rynkowych wymaga analizy dynamiki systemu zarządzania. Stanowi ona podstawę integracji takich obszarów działalności, jak: rynek, zaopatrzenie, produkcja, dystrybucja, inwestycje, prace badawcze i rozwojowe. W miarę kompleksowe podejście do rozpatrywanego problemu wymaga skupienia uwagi na tych składnikach i współzależnościach, które są istotne dla pożądanej właściwości systemu. Podstawowymi elementami takiej analizy są: poszukiwanie analogii, budowa modeli oraz symulacja. Rozważając bowiem jakikolwiek konkretny system, człowiek dąży w istocie do stworzenia w swym umyśle modelu wyjaśniającego zachowanie się obserwowanego systemu (Ansoff 1995, Forrester 1961, Grudzewski, Hejduk 2004, Thompson, Strickland 1993, Żukowski 1990). Systemy konkretne bywają często bardzo złożone; trudno określić ich rzeczywistą strukturę i właściwości. Staramy się wtedy wyjaśnić ich funkcjonowanie na zasadzie analogii między jakimś systemem, który znamy, a systemem badanym. Istotą analogii są relacje równoważności między dwoma systemami. Jeśli ta równoważność obejmuje pewien zbiór elementów i czynników istotnych dla interesujących badającego właściwości wyjaśnianego systemu, to mówi się o dobrej analogii, w przeciwnym wypadku - o analogii złej lub pozornej. Ocena, czy rozpatrywana analogia jest dobra czy zła, nie jest sprawą ani prosta, ani łatwą, szczególnie w wypadku bardziej złożonych systemów, a akceptacja niewłaściwej jest często kosztowna. Jedną z metod eliminowania niewłaściwych analogii jest zdobywanie wiedzy o nich metodą symulacji. Narzędziem umożliwiającym symulację są modele, które powinny odwzorowywać interesujące zależności i właściwości systemu w stopniu wystarczającym dla założonego zakresu badań. Jednocześnie konstrukcja modelu powinna pozwalać na przeprowadzenie badań z możliwością ich powtórzenia w różnych warunkach pracy organizacji gospodarczej [Grudzewski (red.) 1985, Grudzewski, Hejduk 2004, Penc 2006b, Thompson, Strickland 1993, Żukowski 2006].

Analiza dynamiki systemu zarządzania, według J.W. Forrestera (1961), jest metodą badań charakterystyk informacyjnych sprzężeń zwrotnych w działaniu organizacji gospodarczej. Służy ona poznaniu interakcji struktury organizacyjnej na wzmocnienia (w zakresie wytycznych działania) i opóźnienia (w zakresie decyzji i współdziałania), od których wzajemnego oddziaływania zależą sprawność i efektywność pracy całej organizacji. Analizuje się głównie współzależności i oddziaływania między strumieniami: materiałów, zamówień, zleceń, produkcji, wyposażenia, personelu, pieniędzy i innych wielkości - na różnych poziomach i w różnej skali zarządzania (Grudzewski, Hejduk 2002, Penc 2006a, Wagner 1980). Celem podstawowym matematycznoekonomicznego opisu dynamiki systemu zarządzania organizacją gospodarczą, w ujęciu modelowym, jest zobrazowanie metodyki i cech budowy tego typu modeli. Model ten reprezentuje w sposób uproszczony dowolną organizację gospodarczą (produkcyjną). Główną 
uwagę zwraca się na analizę przyczyn fluktuacji zachodzących procesów (określonych wielkości) obserwowanych przy skokowych zmianach, w warunkach rynkowych, potoku zamówień na produkty finalne. Taka analiza powinna eksperymentalnie ujawniać przybliżone ilościowe współzależności między strukturą organizacyjną i wytycznymi działania a stabilnością pracy organizacji gospodarczej. Wyniki symulacji na modelu wskażą pewne właściwości dynamiki zachowania się organizacji gospodarczej (kształtowania się charakterystycznych i interesujących badacza wielkości) w trakcie jej pracy (Forrester 1961, Penc 2000, Żukowski 1990).

\section{Ogólny opis modelu, wytyczne dzialania}

W opisie symboliczno-analogowym przyjętej do rozważań modelowej organizacji gospodarczej (ryc. 1) wyróżniono pięć kluczowych działów i wydziałów, które są reprezentowane przez następujące wielkości (ich poziomy): DS - portfel zamówień (liczba przyjętych zamówień na produkty finalne), DZ - liczba zleceń zakupu materiałów z działu zaopatrzenia, MM - zawartość surowców, materiałów i półfabrykatów w magazynie materiałów, $\mathrm{PR}$ - wielkość produkcji wydziału (zakładu) produkcyjnego i MP - wielkość zapasów produkcji finalnej w magazynie. Sformułowano też niezbędne wytyczne (reguły) działania. Oto wytyczne dla personelu kierowniczego:

1. wielkość produkcji, a ściślej: wielkość zleceń produkcyjnych $(Z P R)$ powinna być taka, aby zapewnić $k$-krotnie wyższy poziom produkcji finalnej w magazynie produktów $(M P)$ w stosunku do uśrednionej liczby przychodzących z rynku zamówień $(Z S)$ na produkty finalne (np. współczynnik wzmocnienia $k=3$ tygodnie). Warunek ten jest spełniany przez przesyłanie do wydziału (zakładu) produkcyjnego $(P R)$ zleceń produkcyjnych $(Z P R)$, stanowiących sumę złożoną z uśrednionej liczby przyjmowanych zamówień $(Z S)$ na produkty finalne i różnicy $\left(S_{l}\right)$ między pożądaną zawartością produktów finalnych w magazynie produktów a jego rzeczywistym stanem. Wielkość $Z P R$ wyznaczymy z formuły:

$Z P R=Z S+S_{1}$

gdzie:

ZS - uśredniona liczba przyjmowanych zamówień,

$\mathrm{S}_{1}$ - zmienna pomocnicza.

Pożądana zawartość produktów finalnych w magazynie produktów $(k \times Z S)$ to iloczyn uśrednionej wielkości zamówień produktów finalnych $(Z S)$ i współczynnika wzmocnienia $(k)$. Współczynnik $k$ określa liczbę tygodni, w ciagu których pożądana zawartość produktów finalnych w magazynie produktów $(M P)$ byłaby wystarczająca do ich wysyłki odbiorcom z prędkością równą średniej prędkości napływania zamówień z rynku. Zmienną pomocniczą $S_{1}$ zatem obliczy się ze wzoru:

$\mathrm{S}_{1}=k \cdot Z S-M P$

gdzie:

$k$-współczynnik wzmocnienia,

$M P$ - faktyczna ilość produktów finalnych w magazynie produktów.

2. w przypadku, gdy poziom materiałów i półfabrykatów w magazynie materiałów $(M M)$, zabezpieczający produkcję, spada poniżej poziomu określonego przez portfel przyjętych zamówień $(D S)$, należy wstrzymać przyjmowanie nowych zamówień na produkty finalne $(Z D S)$; wykorzystuje się tu zmienną pomocniczą $S_{2}$ (ryc. 1);

3. podobnie, jak w wytycznej 2, gdy zawartość materiałów (półfabrykatów) w magazynie materiałów $(M M)$ spadnie poniżej pewnej, z góry określonej wartości $(M i n)$, należy wstrzymać przesyłanie zleceń produkcyjnych $(Z Z R)$ do wydziału (zakładu) produkcyjnego $(P R)$; wykorzystuje się tu z kolei zmienną pomocniczą $S_{3}$ (Żukowski 1990, Żukowski, Winnicki, Grabowiecka 2000) (ryc. 1). 
Zmienna pomocnicza $S_{3}$ wyraża różnicę między aktualną zawartością materiałów i półfabrykatów w magazynie materiałów $(M M)$ a pewnym jego zapasem minimalnym (Min). Zmienna pomocniczą $S_{3}$ obliczy się ze wzoru:

$S_{3}=M M-M i n$

4. wielkość strumienia zleceń na zakup materiałów i półfabrykatów $(Z D Z)$ wysyłanych do działu zaopatrzenia $(D Z)$ musi być równa wielkości strumienia zamówień z rynku sprzedaży na produkty finalne $(R K)$, napływających do działu sprzedaży;

5. w przepustowości informacyjnej prac biurowych czasy przejścia zostały odpowiednio oznaczone: $T Z S$ - czas przejścia niezbędny do uśredniania zamówień na produkty finalne, $T D Z$ - czas przejścia niezbędny do zakupu materiałów, $T P R$ - czas przejścia niezbędny do produkcji, $T D S$ - czas przejścia niezbędny do dystrybucji, $T M P$ - czas przejścia niezbędny do realizacji wytycznej 1.

\section{Matematyczny opis dynamiki systemu zarządzania}

Z rynku sprzedaży produktów finalnych płyną dwa strumienie (ryc. 1); jeden z nich niesie zamówienia na produkty finalne, drugi zaś - informacje o ich wielkości.

Na pierwszym stanowisku decyzyjnym, oznaczonym na ryc. 1 przez poziom $R K$, opisuje się wielkość napływających z rynku zamówień na produkty finalne. Wielkość $R K$ ma charakter skokowy; można ją wyliczyć ze wzoru:

$R K=R K_{0}+Z F \cdot 1(T)$

gdzie:

$R K_{0}$ - początkowa liczba zamówień na produkty finalne,

$Z F$ - liczba napływających do organizacji z rynku zamówień na produkty finalne.

Drugie stanowisko decyzyjne, poziom $Z D S$, reguluje dopływ zamówień na produkty finalne, które można przyjąć ze względu na istniejące zabezpieczenie materiałowe (realizacja wytycznej 2 z wykorzystaniem zmiennej $S_{2}$ ), i jednocześnie koryguje informację o wielkości strumienia tych zamówień przez skierowanie informacji do „uśredniania” zamówień $(Z S)$. Działanie drugiego stanowiska decyzyjnego określa funkcja $F^{*}$ w postaci:

$$
F^{*}= \begin{cases}1, & g d y M M \geq D S \\ 0, & g d y M M<D S\end{cases}
$$

Wielkość $Z D S$ wyliczany z zależności:

$Z D S=F^{*} \cdot R K$

Stanowisko decyzyjne 3, poziom $D S$ (portfel zamówień), określa liczbę przyjętych zamówień na produkty finalne. Wielkość $D S$ obliczymy ze wzoru:

$D S=D S_{0}+T(Z D S-Z M P)$

gdzie:

$D S_{0}$ - poprzednia liczba zamówień na produkty finalne,

$T$ - przedział czasu,

$Z D S$ - wielkość strumienia przyjętych zamówień na produkty finalne,

$Z M P$ - wielkość strumienia zrealizowanych zamówień na produkty finalne.

Stanowisko decyzyjne 4, poziom $Z M P$, reguluje:

- wielkość wysyłki zamówionych produktów finalnych z magazynu $(M P)$,

- wielkość odpowiadającego tej wysyłce odpływu załatwionych zamówień z portfela zamówień na produkty finalne do archiwum. 
Ryc. 1. Symboliczno-analogowy model zarządzania organizacją gospodarczą

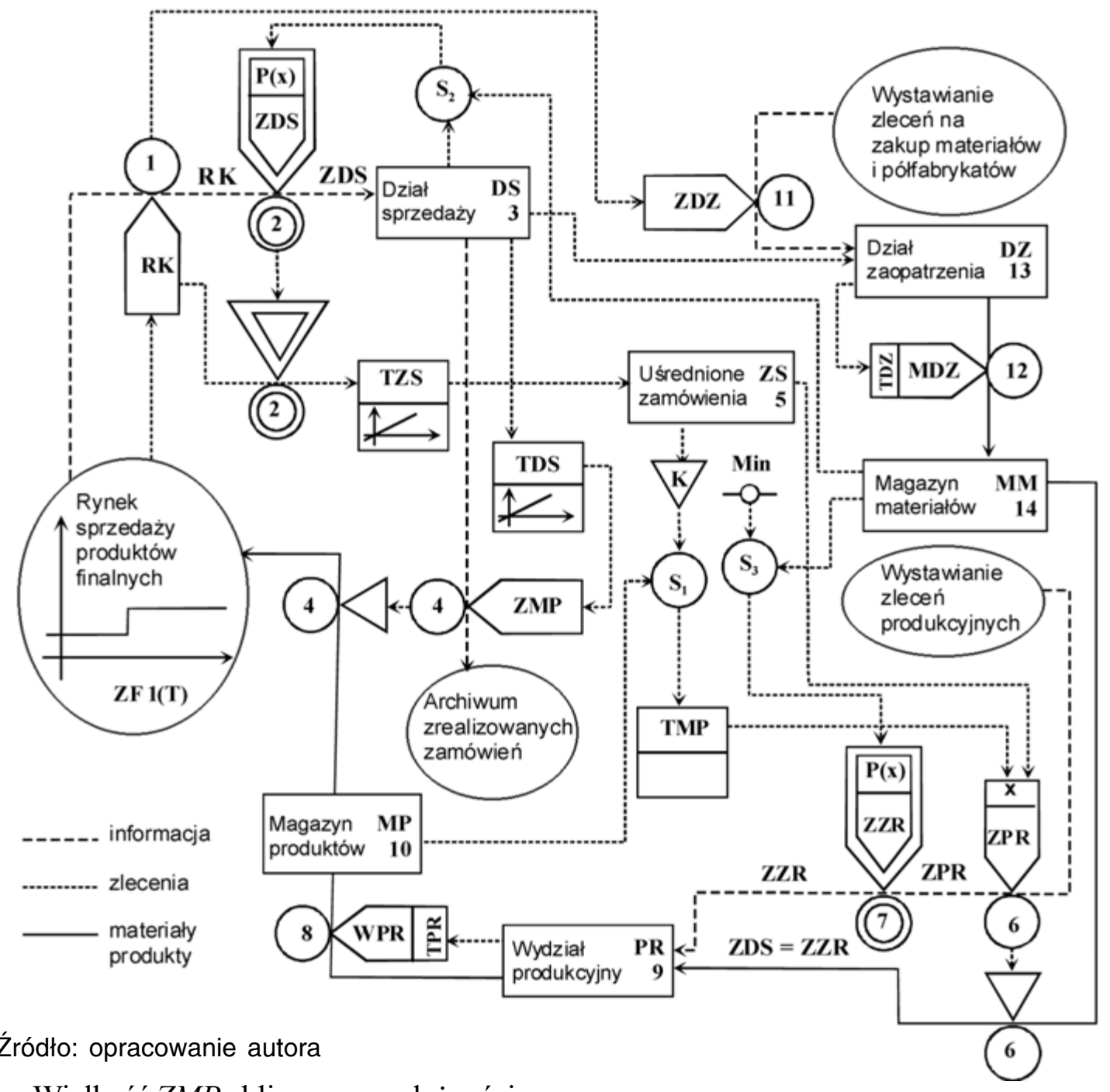

Wielkość ZMP obliczymy z zależności:

$Z M P=D S / T D S$

$D S$ - portfel przyjętych zamówień na produkty finalne,

$T D S$ - czas realizacji zamówienia na produkt finalny (jest wartością stałą, np. 1 tydzień).

Stanowisko decyzyjne 5, poziom $Z S$ (uśrednianie napływających zamówień na produkty finalne), reprezentuje średnią wielkość strumienia napływających z rynku zamówień na produkty finalne $R K$ (z uwzględnieniem korekcyjnego działania 2 stanowiska decyzyjnego - ZDS). Wielkość $Z S$ wyliczymy z formuły:

$$
Z S=Z S_{0}+T\left(Z D S-Z S_{0}\right)
$$

gdzie:

$Z S_{0}$ - poprzednia liczba uśrednienia zamówień na produkty finalne,

$T$ - przedział czasu,

$Z D S$-wielkość strumienia przyjętych zamówień na produkty finalne.

Stanowisko decyzyjne 6, poziom ZPR, reguluje (wykorzystując zmienną pomocniczą $\mathrm{S}_{1}$, zgodnie z wytyczną 1):

- wielkość przepływu zleceń produkcyjnych przesyłanych do wydziału (zakładu) produkcyjnego,

- wielkość strumienia materiałów i półfabrykatów przesyłanych do produkcji $(P R)$, a pobieranych z magazynu materiałów $(M M)$. 
Wielkość strumienia zleceń produkcyjnych $(Z P R)$ jest równa sumie średniej wielkości napływających zamówień na produkty finalne $(Z S)$ oraz poprawce wyrażonej ilorazem wielkości pomocniczej $S_{1}$ i czasu przejścia $T P R$. Wielkość $Z P R$ wyliczymy ze wzoru:

$$
Z P R=Z S+S_{1} / T P R
$$

Stanowisko decyzyjne 7, poziom $Z Z R$, zapewnia realizację 3 wytycznej działania, odcinając dopływ zleceń produkcyjnych przesyłanych do wydziału produkcyjnego, gdy stan materiałów lub półfabrykatów w magazynie materiałów $(M M)$ spadnie do zapasu minimalnego (Min). Działanie stanowiska 7 określa funkcja $P^{*}$ w postaci:

$$
P^{*}= \begin{cases}1, & g d y S_{3} \geq D S \\ 0, & g d y S_{3}<D S\end{cases}
$$

Wielkość ZZR zaś określi się z zależności:

$Z Z R=P^{*} \cdot Z S R$

Stanowisko decyzyjne 8, poziom $W P R$, stanowi element przepustowości wykładniczej pierwszego rzędu i określa czas przejścia potrzebny na produkcję. Przyjmuje się, że ten czas (TPR) jest wartością stałą (np. 2 tygodnie), a elementem akumulującym przepustowość jest zawartość portfela zleceń produkcyjnych $(P R)$. Wielkość $W P R$ obliczymy z zależności:

$W P R=P R / T P R$

Stanowisko decyzyjne 9, poziom $P R$, określa aktualną wielkość portfela zleceń produkcyjnych. Ta wielkość jest równa sumie poprzedniej wielkości zleceń produkcyjnych $\left(P R_{0}\right)$ i akumulowanej różnicy między napływem nowych zleceń produkcyjnych do wydziału $(Z Z R)$ a ich odpływem, równoważnym wielkości produkcji $(W P R)$.

$$
P R=P R_{0}+T(Z Z R-W P R)
$$

Stanowisko decyzyjne 10, poziom $M P$, reguluje zawartość magazynu produktów finalnych; stan magazynu tych produktów jest zasilany strumieniem produkcji $(W P R)$ z wydziału (zakładu) produkcyjnego, a wyjściem jest strumień produktów finalnych $(Z M P)$ wysyłanych przez dział sprzedaży zgodnie z zamówieniami klientów. Różnica między tymi strumieniami jest akumulowana w magazynie produktów finalnych $(M P)$. Wielkość $M P$ określa się ze wzoru:

$$
M P=M P_{0}+T(W P R-Z M P)
$$

gdzie:

$M P_{0}$ - poprzednia zawartość magazynu produktów finalnych.

Stanowisko decyzyjne 11, poziom $Z D Z$, określa wielkość strumienia zamówień (zleceń zakupu) materiałów i półfabrykatów przez dział zaopatrzenia i - zgodnie z wytyczną działania 4 - równa się strumieniowi zamówień na produkty finalne $(R K)$.

Wielkość $Z D Z$ równa jest więc $R K$ :

$$
Z D Z=R K
$$

Stanowisko decyzyjne 12, poziom $M D Z$, reprezentuje strumień materiałów i półfabrykatów zakupionych i dostarczonych do magazynu materiałów $(M M)$ przez dział zaopatrzenia. Wielkość tego strumienia jest regulowana na podstawie liczby zleceń na zakup materiałów i półfabrykatów zakumulowanej w zaopatrzeniu $(D Z)$. Wielkość $M D Z$ określamy z zależności:

$$
M D Z=D Z / T D Z
$$


gdzie:

$T D Z$ - czas przejścia potrzebny na zakup materiałów i półfabrykatów; przyjmuje się go jako wielkość stałą (np. 2 tygodnie).

Stanowisko decyzyjne 13, poziom $D Z$, akumuluje różnicę między napływającym strumieniem zleceń zakupu materiałów i półfabrykatów $(Z D Z)$ a strumieniem ich odpływu, czyli realizacji. Ta ostatnia wielkość jest równoważna strumieniowi materiałów i półfabrykatów zakupionych przez zaopatrzenie $(M D Z)$ i przekazanych do magazynu materiałów $(M M)$. Wielkość $D Z$ wyliczamy ze wzoru:

$D Z=D Z_{0}+T(Z D Z-M D Z)$

gdzie:

$D Z_{0}$ - poprzednia liczba zleceń zakupu materiałów i półfabrykatów.

Stanowisko decyzyjne 14, poziom $M M$, akumuluje różnicę między strumieniem zakupionych materiałów i półfabrykatów ( $M D Z$ ) a strumieniem ich odpływu do produkcji $(Z P R)$. Wielkość $M M$ określamy ze wzoru:

$M M=M M_{0}+T(M D Z-Z P R)$

gdzie:

$M M_{0}$ - początkowy poziom materiałów i półfabrykatów w magazynie.

\section{Interpretacja wyników symulacji}

W symulacji, wykorzystując zbudowany model, zbadano zachowanie się organizacji gospodarczej wówczas, gdy zamówienie na produkty finalne wzrasta o ZF $=40$ jednostek/tydzień przy początkowym poziomie materiałów w magazynie $\mathrm{MM}_{0}=270$ jednostek (ryc. 2).

Ryc. 2. Wyniki symulacji w przypadku wzrostu zamówienia o 40 jednostek/tydzień przy początkowym poziomie materiałów w magazynie 270 jednostek

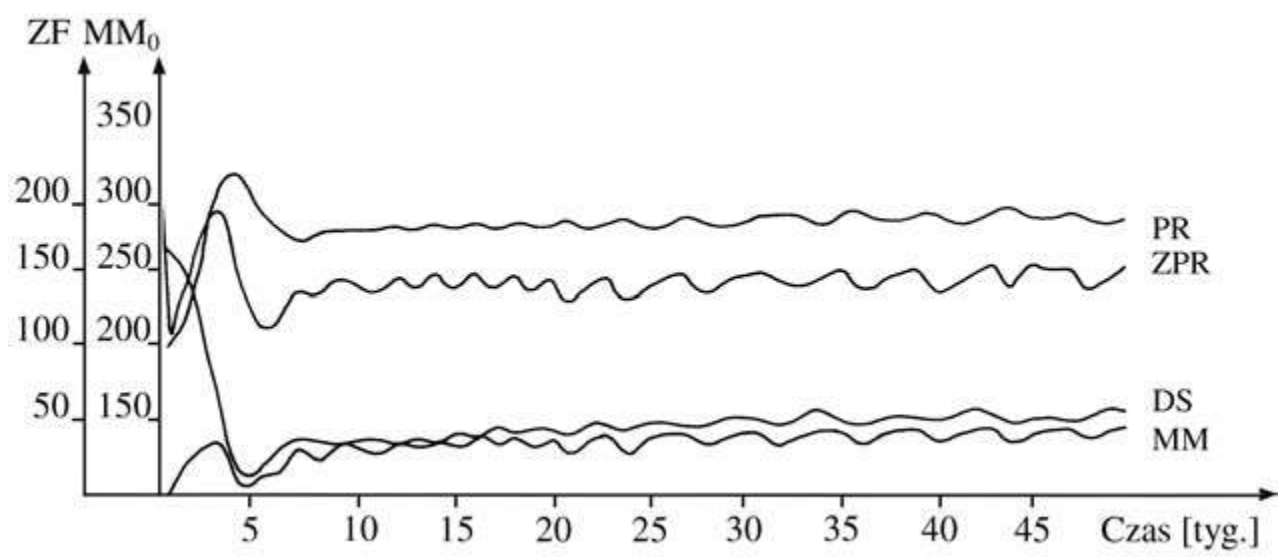

Z wyniku symulacji przedstawionego na wykresie (ryc. 2) płynie wniosek, że przy skokowym wzroście zamówienia na produkty finalne o $Z F=40$ jedn./tydzień zaburzenia przejściowe w pracy opisanej organizacji gospodarczej, wyrażające się wahaniem poziomu produkcji $(P R)$, oraz przepływu zleceń i materiałów na produkcję $(Z P R)$, są obserwowane jeszcze w 35 . tygodniu pracy, przy czym rozpiętość wahań sięga około 10\% średniej ich wartości. Wykres ten wykazuje ponadto przyczynę nadmiernego wydłużania się okresu zaburzeń przejściowych w pracy badanej organizacji gospodarczej. Na wykresie (ryc. 2) widać przenikanie się krzywych wielkości $M M$ i $D S$, co-zgodnie z wytycznymi działania 2 i 3 - powoduje okresowe wstrzymanie przyjmowania 
zamówień na produkty finalne. Efekt ten jest równoważny rynkowym zmianom (wahaniom) wielkości zamówień na produkty finalne; wprowadza on dodatkowe zaburzenia w pracy organizacji gospodarczej. Te zaburzenia - wbrew pozorom - nie są wywołane, jak pokazują wyniki obliczeń (symulacji), przyczynami zewnętrznymi, pochodzącymi z rynku, lecz okolicznościami wewnętrznymi zależnymi głównie od wielkości zamówienia na produkty finalne $(Z F)$ i zapasu początkowego materiałów i półfabrykatów w magazynie $\left(M M_{0}\right)$ (Żukowski, Prusak 1999, Żukowski, Winnicki, Grabowiecka 2000).

\section{Podsumowanie}

Opisany wyżej model dynamiki systemu zarządzania organizacją gospodarczą został zweryfikowany przez porównanie uzyskanych wielkości modelowych z danymi rzeczywistymi pewnego zakładu meblarskiego. Wyniki symulacji na modelu pokazują, że przy skokowym wzroście zamówień na produkty finalne obserwuje się przejściowe zaburzenia w pracy zakładu, wyrażające się przede wszystkim zmianami wielkości produkcji i poziomu przepływu materiałów do produkcji. Te zaburzenia zanikają w różnym okresie, którego długość zależy od wielkości zamówienia na produkty finalne $(Z F)$ i zapasu początkowego materiałów i półfabrykatów w magazynie $\left(M M_{0}\right)$.

Model dynamiki systemu zarządzania organizacją ma znaczenie praktyczne, pozwala bowiem przewidzieć ewentualny okres (w tygodniach) zaburzenia w organizacji gospodarczej w przypadku przyjęcia nadesłanej wielkości zamówienia (oferty) na produkty finalne, przy znanej wielkości początkowej zapasów materiałów i półfabrykatów w magazynie.

\section{Literatura}

1. Ansoff H.I., 1995, Zarzqdzanie strategiczne, PWE, Warszawa

2. Badania operacyjne w organizacji i zarzadzaniu, 1985, W. Grudzewski (red.), PWE, Warszawa

3. Forrester J.W., 1961, Industrial dynamics, Massachusetts Institute of Technology Press, Cambridge

4. Grudzewski W.M., Hejduk I.K., 2002, Przedsiębiorstwo przyszłości - wizja strategiczna, Difin, Warszawa

5. Grudzewski W.M., Hejduk I.K., 2004, Metody projektowania systemów zarzq̨dzania, Difin, Warszawa

6. Penc J., 2006a, Encyklopedia zarzq̨dzania, Akademica, Łódź

7. Penc J., 2000, Kreatywne kierowanie, AW Placet, Warszawa

8. Penc J., 2006b, Podstawy nowoczesnego zarzqdzania, Akademica, Łódź

9. Rue L.W., Holland Ph.G., 1986, Strategic Management: Concepts and Experiences, McGraw-Hill Book Co., New York

10. Thompson A.A., Stricland A.J., 1992, Strategy Formulation and Implementation, Richard D. Irwin, Cambridge

11. Thompson A.A. jun., Strickland A.J., 1993, Strategic Management: Concepts and Cases, Richard D. Irwin, Boston

12. Wagner H.M., 1980, Badanie operacyjne, PWE, Warszawa

13. Żukowski P., Postrojenije i issliedowanije dinamiczieskoj modieli uprawlenija miebielnym priedprijatijem (sistiemnyj podchod), „Lesnoj Żurnał” 2/1990

14. Żukowski P., Prusak Z., 1999, Design and Analysis of the Dynamic Management Model of a Manufacturing Company [In:] The 15 th International Conference on Production Research: Manufacturing for a Global Market (Ed. M.T. Hillery \& H.J. Lewis), University of Limerick, Limerick (Ireland)

15. Żukowski P., Winnicki K., Grabowiecka R., 2000, The Management Model of an Agriculture Company. [In:] Проблемы упраления агропромышленным комплексом России (Problemy zarzadzania agroprzemystowym kompleksem Rosji), m. III - Теория и практика упраления предприятиями АПК, Российская академия сельскохозяйственых наук, Всероссийский научно-исследовательский институт экономики сельского хозяйства, Санкт-Петербург

16. Żukowski P., 2006, Podstawy nauk o zarzadzaniu, Oficyna Wydawnicza Politechniki Rzeszowskiej, Rzeszów 


\section{Model of Dynamic and Simulation of the Management System in Business Organization}

This work describes dynamic model and simulation of a manufacturing company that manage operations, and analysis the reasons for changing processes inside the company in accordance with a change in the stream of incoming orders for finished products. Results of computer simulation of the designed model, show some dynamic characteristics within different divisions of the entire manufacturing company throughout duration of the production process. In the model of a production facility, different departments were taken into account. The departments are involved in activities related to flow of information, materials and prefabricated elements, production, products storage, and shipment. 